\title{
O VIDRO DA PALAVRA: O ESTRANHO COMO OBJETO-LIMITE ENTRE A LITERATURA E A PSICANÁLISE
}

Ana Maria Portugal Maia Saliba*

RESUMO:

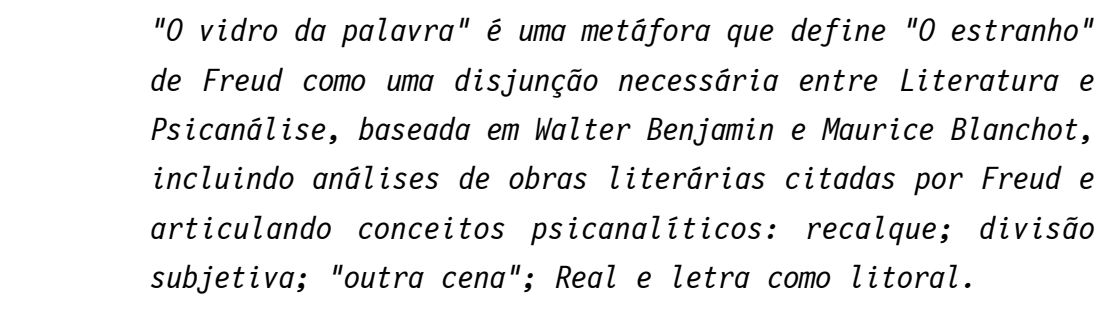

PALAVRAS-CHAVE: Literatura e Psicanálise, "O estranho" (Freud), Letra como litoral (Lacan), Walter Benjamin, Maurice Blanchot.

0 ensaio de Freud Das Unheimliche (1919) - "0 estranho" - traduz uma atmosfera estranho-familiar, ao referir-se a inúmeros textos literários de títulos misteriosos, paradoxalmente ao lado de exemplos pessoais e de autores clássicos como Schiller, Shakespeare, Heine, Mark Twain e outros. Tudo isso para chegar à breve conclusão de que o Unheimliche está diretamente ligado ao recalcado inconsciente.

Entretanto, rastreando os textos ficcionais citados, outros caminhos se vislumbram, conduzindo-nos a 3 autores: Borges, Benjamin e Blanchot. Pois o estranho, o Unheimliche, pertence, de maneira muito especial tanto à psicanálise quanto à literatura, onde, além de ampliar as ocorrências do cotidiano, situa-se não somente naquilo que contém mistério, angústia e terror, mas, segundo Borges, associa-se também ao limbo dos poetas, só de letras, como aquelas paisagens "de horror tranqüilo e silencioso" do castelo de seus ensaios dantescos. (Borges, 1999: 381)

* Doutora em Letras: Estudos Literários (Área de concentração: Literatura Comparada), 2003. 


\section{EM TESE}

Belo Horizonte, v. 8, p. I-243, dez. 2004

0 texto de Freud nos apresenta o campo do Unheimliche como uma palavra - privilégio da língua alemã -, um sentimento, um efeito, uma impressão, uma característica. A Unheimlichkeit - estranheza ou estranhamento - remete à Hilflosigkeit, ao desamparo que cerca os estados do sonho e às repetições estranhas, impondo algo fatídico e inescapável a que chamamos "acaso". Isto porque, desde a raiz do Unheimliche no Heim (casa, lar), é uma estranheza familiar que toca à experiência do Real na implicação de cada um em relação ao tempo sem memória da constituição do ser na linguagem.

Na equivalência entre das Unheimliche (o estranho) e das Unbewusste (o inconsciente), o prefixo da negação un-, comum a ambos, é a marca do recalque. Na pulsação do tempo não linear, que caracteriza o inconsciente, revela-se o inédito, o que espera por uma tradução: é aí que a ficção sobre o estranho apóia-se nos fatos do inconsciente, principalmente em seu fundamento inapreensível e intraduzível. A tradução, em estado constante de privação e falha, permanece, na equivocidade do termo benjaminiano die Aufgabe (Benjamin, 1980), uma tarefa / renúncia / missão privilegiada, única capaz de, através da "distração", planar por paragens inéditas, dando lugar a deslizamentos, saltos e estranhezas que caracterizam o incognoscível. Por esta razão, com a psicanálise, propomos para o Unheimliche uma "tradução distraída".

"Zwei Seelen wohnen, ach! in meiner Brust." (Duas almas habitam, ah! o meu peito) - diz o poeta na voz de Fausto. (Goethe, versos 1072/3) Freud acrescenta que a divisão descoberta pela psicanálise não é apenas esta que os poetas lamentam, isto é, uma rejeição crítica às paixões, mas acontece entre o eu e o recalcado inconsciente, havendo aí uma cesura radical. (Freud, 1919: 248)

Na ficção estudada no Unheimliche surge o duplo como a impossibilidade de esquecer o desejo; e a "outra cena" (Freud, 1900: 541; Lacan, 1966: 628), presença do Outro que nos aliena de nós mesmos, constrói o pacto ficcional nos artifícios da suposição. São estranhezas que fazem parte da bagagem do escritor, são sua otredad constitutiva (Paz, 1995: 182), estando em suas mãos manter sob tensão um tênue fio de imaginário, nem firme, nem frouxo demais, apenas o suficiente para que o estranho não se torne nem excessivamente fantástico, nem asseguradamente familiar. 
Hélène Cixous se refere ao Unheimliche de Freud como um "estranho romance teórico"(Cixous, 1974: 14), sugerindo que o próprio texto se contamina pelo tema que desenvolve, destilando estranheza a cada passo. Freud está tocado pelo estranho, rendendo-se ao poder de atração do trabalho de seus deuses, os escritores. Como "narrador estranhado" deixa-se conduzir pela mão da escrita, apresentando-nos - e isso transparece em outras passagens de sua obra - um texto entrecortado de saltos com citações aparentemente arbitrárias, provocando estranhamento.

De acordo com Georg 0tte, a citação, em si, já é uma fragmentação do texto, pois não significa citá-1o em sua integridade, e nem se limita à sua repetição literal, mas "chama", via metonímia, todo o texto de origem, do qual ela foi extraída. No entanto, é o próprio estranhamento que impele o leitor à procura do parentesco escondido na "bagagem" do fragmento citado. A interrupção aparentemente destrutiva do contexto presente se transforma na construção de uma totalidade maior, que exige um leitor atento e ativo: é a atenção aguçada da "presença do espírito" - na expressão benjaminiana. (0tte, 1996: 218-219) "Em minha obra escreve Benjamin- as citações são como os salteadores, que, de mãos armadas, assaltam o leitor e roubam-1he a adesão." (Benjamin, 1995: 61)

Um exemplo é a citação, por Freud, do dito popular "Liebe ist Heimweh" (Amor é saudade da casa), em conexão com a estranha familiaridade do corpo materno, a antiga pátria (Heimat) da criança humana, onde, a princípio, cada um se encontrou certa vez. (Freud, 1919: 258) Esta citação é o protótipo de outras, disseminadas pelo texto freudiano, nas quais, onde há um impasse no encadeamento linear da teoria - certamente pela presença do Real - há um "chamado" a autores literários, e para estes somos lançados a fim de apreender a relevância do que este "salto" nos traz.

0 amor, mesmo insaciável, violento e impossível - como mostra a literatura e a clínica da psicanálise o testemunha - ainda assim, é o que faz suplência para possibilitar ao desejo inconsciente uma encenação de suas vicissitudes, exigindo, por sua vez, as artimanhas do encobrimento do objeto e a articulação dentro dos parâmetros da família humana, sendo o Édipo, na teoria freudiana, o paradigma exemplar.

Na escrita benjaminiana surgem os anjos efêmeros da tradição talmúdica, segundo a qual, são criados a cada instante para, depois de terem cantado seu hino 


\section{EMTESE}

Belo Horizonte, v. 8, p. I-243, dez. 2004

na frente de Deus, cessar e desaparecer no nada. Introduzem na cronologia linear uma cesura imperceptível, para que outra história possa dizer-se, entrecortada, lacunar, feita de sobressaltos e de espasmos: uma narrativa descontínua, frágil, e sempre ameaçada pelo esquecimento. (Gagnebin, 1997: 123-124) Esses aspectos dos anjos benjaminianos, o jubilatório e o aniquilador são inseparáveis, trazendo, com sua discrição e evasão, a verdadeira atualidade: fulgurante, evanescente e destruidora, que corresponde ao instante do Einfall (achado), termo privilegiado desde os românticos de Jena (Seligmann-Silva,1999: 39) e que une novamente psicanálise e literatura. No método da psicanálise, o Einfall, expressando o que ocorre à mente, sem, a princípio, uma conexão muito clara, é destacado por Freud como o mais importante da associação livre.

"Ange = étrange, estrange = étranger..." escreve Paul Valéry, ao que Lacan, sobre o trabalho do analista perfurando a face serial do significante, acrescenta: étrange, être-ange (Lacan, 1975: 12), e nós deslizamos para lettreange, letra-anjo: a perda do sentido por esse corte que o "estranjo" fulgurante e aniquilador introduz impulsiona ao trabalho da escritura, marcando a letra da experiência estranha como 1itoral. (Lacan, 2001)

Na psicanálise, aí se situam o sentimento de estranheza e o Real como "ex-sistente", proposto por Lacan (1973-1974). Nas teorias da narração e da escritura, encontramos a associação com a morte e, essencialmente, o "exterior" proposto por Maurice Blanchot (1980: 95). A morte do autor mostra a escritura como esse neutro - diz Barthes - esse oblíquo aonde foge o nosso sujeito, aonde vem se perder toda identidade. "Quando se produz esse desligamento, o autor entra em sua própria morte, e a escritura começa". (Barthes, 1980: 65)

Diz Benjamin: "0 olhar profundo da melancolia transforma objetos e obras em excitante escrita". Com essa doutrina barroca destroem-se o contexto natural das coisas e a continuidade aparente entre natureza e história, que agora se apresentam como mero amontoado de signos arbitrários. Justamente pelo fato de a morte ser, em si, isenta de significado, ela dá condição de dar significado aos signos, e representa o ponto de indiferença: não apenas os objetos que entram na escritura estão mortos; também o autor está presente apenas como outro, como morto. 0 texto, desenvolvido como uma estrutura policêntrica, tem tantos centros quantos 
leitores-escritores. Sua leitura é uma reescritura na própria atualidade. (Witte, 1992: 86)

Quanto ao "exterior" de Blanchot, o "extra" do estranho, acentuado pelas traduções nas várias línguas, faz progredir a escritura em direção ao semmemória, ao "passado imemorial" e ao "inconcebível", já apontado por Benjamin em vários de seus ensaios. A psicanálise privilegia a escrita na memória, mas visa destacar a presença do "incognoscível" (o Unerkannt, o Urverdrängt) e do acaso, que indicam o Real.

Entre psicanálise e literatura, a diferença se localiza na maneira de lidar com os vestígios, pois, para a primeira, eles devem promover a implicação de um sujeito em relação ao desejo. Na escritura, o movimento é quase contrário. Blanchot fala de "quatro ventos": "exterior, neutro, desastre, retorno", que, pela escritura, levam o pensamento a se deixar desligar até o fragmentário. (Blanchot, 1980: 95) Na via do estranho, a psicanálise força o apagamento das pegadas com a redução do imaginário e da fantasia, ponto onde se fixará uma letra, marca de perda, e que, paradoxalmente, em sua função para além do simbólico, destaca-se do significante e pode tornar-se uma "segunda aquisição" (Rilke).

0 inesquecível não se liga à recuperação da lembrança, mas a seu apagamento. Ao contrário do que pode parecer, a função do esquecimento é conservar a lembrança, pois o pensamento só pode acolher o que traz em si, esquecendo. Assim, quanto aos vestígios, lidar com eles de uma ou de outra maneira, faz a diferença entre o esquecimento que conserva e arquiva, e o verdadeiramente inesquecível. É a diferença entre o estranho que se torna familiar - por ligar-se ao recalcado (no dizer de Freud) ou visando compreendê-1o - e o familiar imemorial que sempre foi estranho e inédito, não podendo ser esquecido.

0 inesquecivel se refere a restos não simbolizados, como no filme Shoah de Claude Lanzmann sobre o holocausto, onde os trilhos e caminhos de pedras têm a função de testemunhas mudas e pobres, que não provam nada (e até poderiam ser falsas), não envelhecem nem morrem, e não têm como responder aos apelos do presente. "As pedras, símbolo da mudez em várias culturas, paradoxalmente passam a ser a representação adequada do holocausto, uma vez que se trata de uma mudez eloqüente: dizem o indizível." (0tte, 2002) 


\section{EMTESE}

Belo Horizonte, v. 8, p. I-243, dez. 2004

Blanchot, no livro A escritura do desastre - onde desastre não se refere a catástrofe ou acidente, mas a des-astre, ruptura com o astro -, reporta-se ao apagamento dos vestígios como "a morte impossível necessária", pois não se vive e não se fala senão matando em si mesmo o infans, a criança maravilhosa e terrível que nós fomos nos sonhos e desejos daqueles que nos viram nascer. (Blanchot, 1980: 112) Isso constitui algo impronunciável, que se torna uma narrativa: é onde o sujeito, no trabalho analítico, constrói a fantasia fundamental. Conservar apenas a inesquecível passagem do Real seria a escritura do des-astre, ruptura com o astro, esquecimento sem memória.

Quanto ao impronunciável ou o desconhecido, a escritura preserva, ao máximo, a nudez do vestígio, sua lisura, sua pura e simples condição de marca gravada: Unheimliche / Unbewusste, onde o estranho e não-conhecido é na verdade conhecido de velho, é familiar. E então o narrador blanchotiano se pergunta: "Será que foi um tal sentimento que me tornou estrangeiro naquele instante, provocou uma queda, uma vertigem na qual, longe de repelir o aterrador, eu me encontrava perto dele, unido a ele pela simpatia, pelo desejo de reconhecê-10?" (Blanchot, 1953: 74-75)

0 fenômeno da angústia é esse surgimento do hóspede desconhecido, unheimlich, que, de certa maneira, nunca passou por um reconhecimento. Mas que não engana. Literatura e psicanálise trabalham para dar-1he forma no campo do semblant - suposição e fingimento - na lida com o Real. Em ambas a questão do falso / verdadeiro sempre permeou a experiência, sendo o Unheimliche - o estranho - o ponto em que a ficção é bem real, como o abraço imprevisto do objeto $a$ - causa de desejo - em plena trama da ficção.

0 apagamento das pegadas nos leva à metáfora do vidro, este material frio e liso, no qual, como lembra Benjamin, os vestígios se tornam manchas, que podem ser apagadas (Benjamin, 1995 [1933]:117), e que é tomado por Blanchot como superfície que separa, mas não oculta, onde o secreto e o privado se desnudam, mantendo, no entanto, o isolamento e a inacessibilidade. Diz Blanchot:

\footnotetext{
"a palavra 'estranho' está aqui no seu lugar. A estranheza consiste no fato de 0 fenômeno do vidro, de que falei, se aplicar a tudo, mas principalmente aos seres e aos objetos de um certo interesse. (...) o meu prazer na realidade estava sob um vidro, podia vê-los, apreciá-los, mas não usá-los. Do mesmo modo se encontrasse uma pessoa que me agradava, tudo que me
} 
acontecia com ela de agradável estava sob vidro, e, por causa disso, inutilizável, mas também longínquo e num certo passado." (Blanchot, 1988: 56)

0 estranho surge no levantar das cortinas como um enquadramento da angústia, do desamparo e da solidão. 0 estranho está lá sob o vidro, deixando inquieto aquele que escreve, permitindo, com a palavra, um contato "outro": o "vidro da palavra". Os vestígios vêm do vento, do exterior, do Outro, do neutro. Mais que tudo, é o des-astre que vela.

Presença do nada. 0 vento é sopro, grito e fala, invadindo a escrita, marcando as palavras em seu vidro, este motivo já presente, em sua estranheza e aproximação, em vărias passagens do texto exemplar do Unheimliche, "0 Homem de Areia" de Hoffmann: por detrás dos óculos, das lentes do demoníaco Coppola e até na voz de 01 ímpia, tão peculiar que evocava sinos de vidro. A personagem Clara, evocada como anjo, ao final do conto impele à travessia do vidro, pois "estranjamente", ao ver a gigantesca sombra da torre projetando-se na praça do mercado, convida Natanael a subir nas alturas, de onde ele se projeta, desconhecendo a balaustrada, e atraído pelo nome inexorável do Real. Rompeu-se o semblant desenhado pela sombra da torre.

Coube ao escritor fazer, com o Unheimliche, litoral.

Depois, muito tempo depois é que Freud inventa a psicanálise e, por meio dela, o analista, esse "estranjo", assume por tarefa produzir uma escrita, sustentandoa em sua dimensão de letra-litoral. 0 vidro da palavra é o Unheimliche - o estranho - como litoral entre psicanálise e literatura.

ABSTRACT :

Based on Walter Benjamin and Maurice Blanchot, this paper uses a metaphor - "The word's glass" - to define Freud's "The Uncanny" as a necessary disjunction between Literature and Psychoanalysis. I also analyze some literary works and study psychoanalytical concepts such as "repression", "splitting", "the other scene", "Real" and "letter as littoral".

KEY WORDS: Literature and Psychoanalysis, The Uncanny (Freud), Letter as littoral (Lacan), Walter Benjamin, Maurice Blanchot. 


\section{EM TESE}

Belo Horizonte, v. 8, p. I-243, dez. 2004

\section{REFERÊNCIAS BIBLIOGRÁFICAS}

BARTHES, Roland. O rumor da língua. Trad. Mário Laranjeira. São Paulo: Editora Brasiliense, 1988.

BENJAMIN, Walter. Die Aufgabe des Übersetzers (1921). In: Gesammelte Schriften. Frankfurt am Main: Suhrkampf Verlag, 1980, v.IV / 1. p. 9-21.

- Rua de mão única. In: Rua de mão única. 5. ed. Trad. Rubens Rodrigues Torres Filho e José Carlos Martins Barbosa. São Paulo: Brasiliense, 1995. p. 9-70.

- Experiência e pobreza (1933). In: Rua de mão única. 5. ed. Trad. Rubens Rodrigues Torres Filho e José Carlos Martins Barbosa. São Paulo: Brasiliense, 1995. p. 114-119.

BLANCHOT, Maurice. L'écriture du désastre. Paris: Gallimard, 1980.

- Celui qui ne m'accompagnait pas. Paris: Gà̄ìmard, 1953.

- Morte suspensa (1948). Trad. Jorge Gamacho. Lisboà: Edições 70, 1988.

BORGES, Jorge Luis. Nove ensaios dantescos (1982). In: obras completas. Vários tradutores. São Paulo: Globo, 1999. v.III. p. 381-421.

CIXOUS, Hélène. Prénoms de personne. Paris: Seui1, 1974. FREUD, Sigmund. Die Traumdeutung (1900). 6.Aufl. Frankfurt am Main: Fischer Verlag, 1976. (Gesammelte Werke, 2-3).

. Das Unheimliche (1919). In: Werke aus den Jahren 1917-1920. 5. Aufl. Frankfurt am Main: Fischer Verlag, 1978. (Gesammelte Werke, 12). p .227-268.

GAGNEBIN, Jeanne-Marie. Sete aulas sobre linguagem, memória e história. Rio de Janeiro: Imago, 1997.

LACAN, Jacques. La direction de 1 a cure et les principes de son pouvoir (1958). In: Écrits. Paris: Seuil, 1966. p. 585-646.

. Le séminaire. Livre XX. Encore (1972-1973). Paris: Seuil, 1975. inédito.

. Les non-dupes errent. Paris, 1973-1974. Seminário

- Lituraterre. In: Autres écrits. Paris: Seuil, 2001. p. 11-20.

OTTE, Georg. "Rememoração e citação em Walter Benjamin". Revista de Estudos de Literatura. Dossiê América Latina, Belo Horizonte, FALE / UFMG, v. 4, p. 211-223, out. 1996.

"A mediação pelos vestígios - os comentários de Beatriz Sarlo sobre Shoah, de Claude Lanzmann". Anais do VIII Congresso Internacional ABRALIC, UFMG, Belo Horizonte, jul. 2002.

PAZ, Octavio. El arco y la lira. In: La casa de la presencia. 1. reimpresión. México: Fondo de Cultura Económica, 1995. p. 33-288.

SELIGMAN-SILVA, Márcio. Ler o livro do mundo. Walter Benjamin: romantismo e crítica literária. São Paulo: Iluminuras, 1999.

WITTE, Bernd. "0 que é mais importante: a escrita ou o escrito?" Trad. Georg Bernard Sperber. Dossiê Walter Benjamin. Revista USP, São Paulo, n. 15, p. 85-89, set. out. nov. 1992. 